\title{
UTILIZAÇÃO DE FERRAMENTAS EMERGENTES PARA TRANSFORMAÇÃO E VISUALIZAÇÃO DE DADOS NA ÁREA DA SAÚDE
}

\author{
Bruno M. P. Pereira, Gilberto M. Yabiku Jr., Karen C. Abrão e Johannes V. Lochter \\ Departamento da computação, Centro Universitário Facens, Sorocaba/SP - Brasil
}

\begin{abstract}
RESUMO
Nos últimos anos, a geração de dados tem aumentado rapidamente devido a digitalização de muitas atividades tanto pessoais quanto empresariais. Por esse motivo, a área de análise de dados tem se desenvolvido abundantemente, já que existe uma grande necessidade de organizar, atribuir significados e facilitar a visualização de tais dados de forma a auxiliar uma tomada de decisão. Com base nesses princípios, o objetivo do atual projeto é estudar ciência de dados e colocar em prática conceitos teóricos desse ramo da ciência por meio da construção de gráficos e visualizações. Para tanto, foram utilizadas as tecnologias emergentes Dremio para fazer as transformações de dados e o Superset para a construção das visualizações. Foram utilizadas massas de dados públicas disponibilizadas de modo gratuito na internet por instituições governamentais para que, desse modo, o projeto possa ter maior semelhança possível de um cenário real. Portanto, este trabalho poderá auxiliar de forma ativa na área da saúde, nele foi analisado o padrão de ocorrência da SARS-CoV-2 (COVID-19) em uma área e determinou-se quais os grupos foram mais afetados.
\end{abstract}

\section{PALAVRAS-CHAVE}

Dados Abertos, Ciência de Dados, Saúde, Tecnologias Emergentes

\section{INTRODUÇÃO}

A humanidade caminha para o que está sendo chamado de $4^{\mathrm{a}}$ Revolução Industrial, ou revolução da robótica, que se caracteriza por um conjunto de tecnologias que permitem a fusão do mundo físico com o digital, como inteligência artificial, Big Data e robótica. Portanto, existe crescente demanda de organizar os dados, atribuir significados a eles e facilitar a sua visualização de forma a auxiliar na tomada de decisão.

O tema ganha maior relevância quando uma pesquisa mostra que, "Em 2013 apenas 22\% de todos os dados digitais armazenados eram úteis para serem analisados e menos de 5\% foi de fato analisado. Estima-se que em 2020, apenas 35\% dos dados sejam úteis se forem rotulados." (EMC, 2020). Ou seja, a qualidade da informação se tornou o maior obstáculo do setor, motivo pelo qual vem recebendo recebido tantos investimentos.

No contexto de Big Data, os conceitos de Data Warehouses e Data Lakes são importantes. Para serem inseridos em um Data Warehouse, os dados são formatados na entrada para padrões definidos. Por esse motivo, os Data Warehouses possuem potencial limitado, são bases de dados estruturadas construídas visando uma estratégia e em busca de objetivos específicos. Já os Datas Lakes possuem dados mais parecidos com a vida real, provenientes de diversas fontes, com formatos diferentes, o que aumenta seu potencial para gerar novas ideias. $\mathrm{O}$ acesso aos dados brutos abre possibilidade de um grande número de combinações diferentes e os dados são transformados somente quando usados (Red Hat, 2020).

Benefícios dessa nova era digital já podem ser vistos dentro do campo governamental. As inovações feitas com base nos dados têm melhorado a eficiência da gestão e a qualidade das políticas públicas, dando maior inteligência aos processos. Como exemplo, em 2019 foi lançado o projeto "Em frente Brasil", composto por quatro ferramentas: o Sinesp Big Data, o Sinesp Geo Inteligência, o Sinesp Tempo Real e o Sinesp Busca, desenvolvidas pela Universidade Federal do Ceará (UFC) em parceria com o Governo Federal Brasileiro. Dentre suas funções, destacam-se o georreferenciamento de ocorrências, visualização de mapas de 
calor e rotas de policiamento e monitoramento inteligente por câmeras (Ministério da Justiça e Segurança Pública, 2020).

Uma área importante que beneficia toda a sociedade e que ainda é pouco explorada é a saúde. Os dados oriundos dos sistemas de saúde ao redor do mundo são precariamente utilizados, justificado pelo difícil acesso na maioria dos países. No Brasil, a realidade de dados abertos é diferente. Os dados do Sistema Único de Saúde são amplamente disponibilizados e várias iniciativas surgiram recentemente para explorar a abundância de dados (Freire, Souza and Almeida, 2015).

O principal objetivo deste trabalho é trazer à luz evidências da utilização de tecnologias emergentes para transformar e visualizar dados de fontes diversas de maneira eficiente para a área de saúde. Será utilizada uma massa de dados públicos disponibilizada de modo gratuito na internet por instituições governamentais brasileiras com o objetivo de alcançar maior semelhança possível de um cenário real. O restante deste trabalho está organizado da seguinte maneira: na Seção 2 é apresentado o desenvolvimento do trabalho, trazendo referências teóricas sobre a metodologia e os sistemas de suporte empregados; na Seção 3 são apresentados os resultados coletados, as análises elaboradas sobre estes; finalmente, na Seção 4 é apresentada a conclusão e trabalhos futuros.

\section{METODOLOGIA E DESENVOLVIMENTO}

Entre as ferramentas disponíveis, foram consideradas as gratuitas e mais populares. Por uso gratuito, buscou-se habilitar um número maior de setores a se beneficiar deste trabalho. Por mais populares, foram consideradas aquelas em ascensão e com uma base consistente de suporte e desenvolvimento por trás da ferramenta.

O Dremio (2020a) é uma ferramenta de código aberto construída utilizando o Apache Arrow (2020). Ele unifica diversas ferramentas de inteligência de negócios, como Tableau e Power BI, assim como bases de dados de arquiteturas diferentes, como Data Lakes e Data Warehouses, entre as quais o Data Lakes habilita maior conectividade por não se limitar a extensões de arquivos específicos (Dremio, 2020b).

Tecnicamente, o Dremio é um Data Lake Engine e, em comparação com seus concorrentes que são serviços de Cloud Data Warehouses (Redshift, Snowflake) e mecanismos de consulta no bando de dados (Presto, Athena), possui vantagem de realizar consultas mais velozes e possibilita a redução de custo de infraestrutura por ser baseado no Apache Arrow.

Neste projeto, foram utilizados conjuntos de dados de diversas fontes. Do portal Sistema IBGE de Recuperação Automática (https://sidra.ibge.gov.br/pesquisa/censo-demografico/) foram retiradas informações sobre a população estimada para cada estado, qual a quantidade de pessoas vivendo em áreas rurais e urbanas em cada município brasileiro e sua faixa etária. Do portal Brasil.io (https://brasil.io/dataset/covid19/caso_full/) mantido por voluntários foi utilizado o conjunto de dados relativo a SARS-CoV-2 (COVID-19) que continha dados sobre casos e óbitos por município. Dentro desse cenário dos dados de COVID-19, o estado brasileiro São Paulo foi removido de algumas visualizações, pois apresentou dados fora da distribuição comum aos outros estados (ponto fora da curva), prejudicando a avaliação e visualização.

Os dados referentes ao saneamento básico brasileiro são do portal Painel Saneamento (https://www.painelsaneamento.org.br/). Dele foram usados dados sobre o acesso a água canalizada e sobre a coleta de esgoto por município. Do portal da OMS (https://covid19.who.int/) foram coletados os dados Globais da COVID-19.

Esses dados estavam originalmente no formato Excel e CSV e foram convertidos para o formato Apache Parquet pela ferramenta do Dremio. Para construir as visualizações, foi utilizada a ferramenta Apache Superset (2020) de código aberto, por ser intuitiva e ter opções para construir gráficos robustos e dashboards interativos.

Todas essas soluções foram implementadas em uma máquina virtual do Debian 10 hospedada na nuvem pela Digital Ocean (https://www.digitalocean.com/) utilizando os Containers do Docker (https://hub.docker.com/r/preset/superset) para o $\quad$ Apache Superset (https://hub.docker.com/r/dremio/dremio-oss) para o Dremio. Apesar do número de passos, o processo é simples, podendo ser implementada em diversos ambientes, requerendo apenas executar uma rotina de comandos no terminal do Linux (Sankaran, 2020). 


\section{RESULTADOS E ANÁLISES}

Com a base de dados dos casos de COVID-19 foi feita uma visualização onde pode-se acompanhar os casos acumulados por semana e por estado entre o período de 1 de janeiro de 2020 até 24 de julho de 2020 (Figura 1). Nesse gráfico nota-se que a quantidade de casos aumentou rapidamente no mês de junho, sendo que as unidades federativas que se destacaram foram Distrito Federal, Rio de Janeiro, Bahia e Ceará; Junto a Figura 1, em seu lado esquerdo, é possível observar a interface do Superset com as configurações usadas para montar a visualização, basicamente ele se comporta como uma query no SQL, deve-se escolher os atributos a serem exibidos, a função que se quer aplicar a eles e filtrar os resultados se necessário.
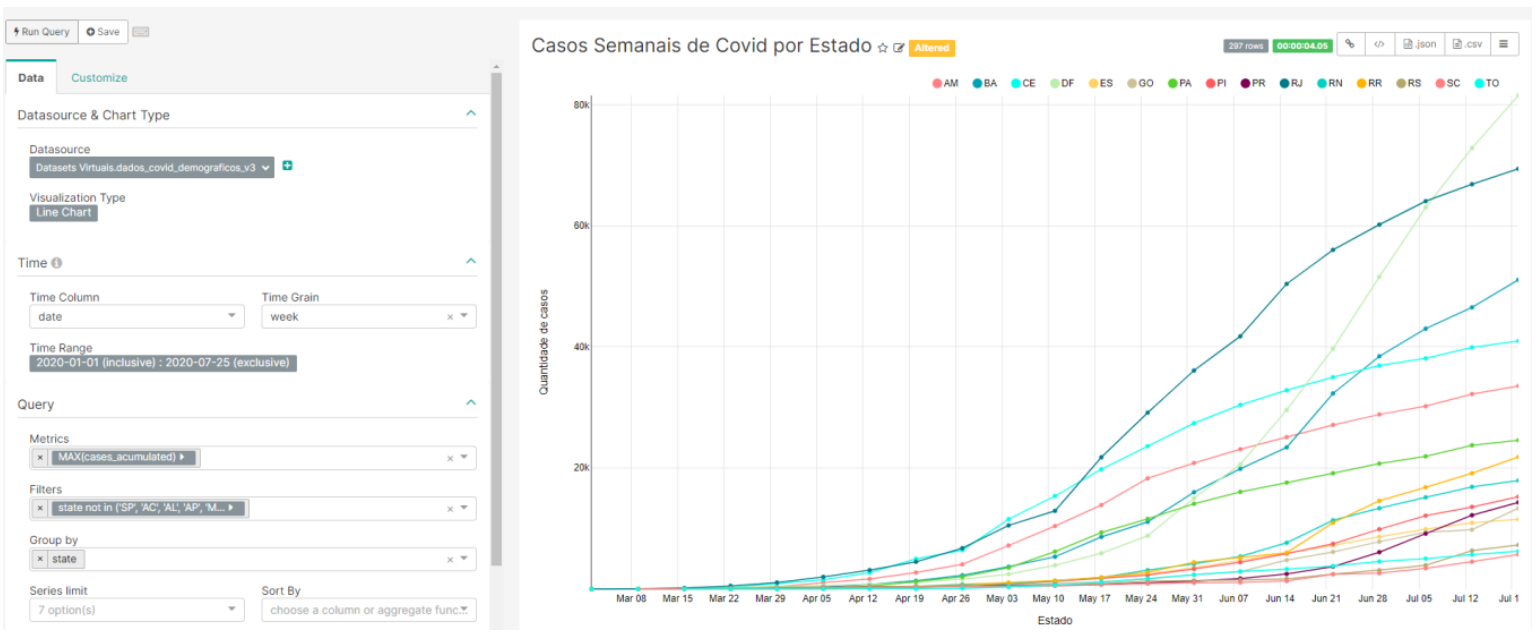

Figura 1. Casos semanais da doença COVID-19 por estado brasileiro

Foi desenvolvido um gráfico com os dados de acesso à água canalizada, acesso à coleta de esgoto e população total estimada para cada estado, sendo os mesmos representados nessa ordem respectivamente nas barras para cada estado na Figura 2. Verifica-se que o índice de pessoas sem acesso ao saneamento básico é muito alto entre os estados das regiões Norte e Nordeste. De acordo com o diagnóstico disponibilizado pelo Sistema Nacional de Informações sobre Saneamento (SNIS) em 2018, $48 \%$ da população brasileira não possuía coleta de esgoto, consistindo em um número elevado como pode ser visto representado no gráfico.

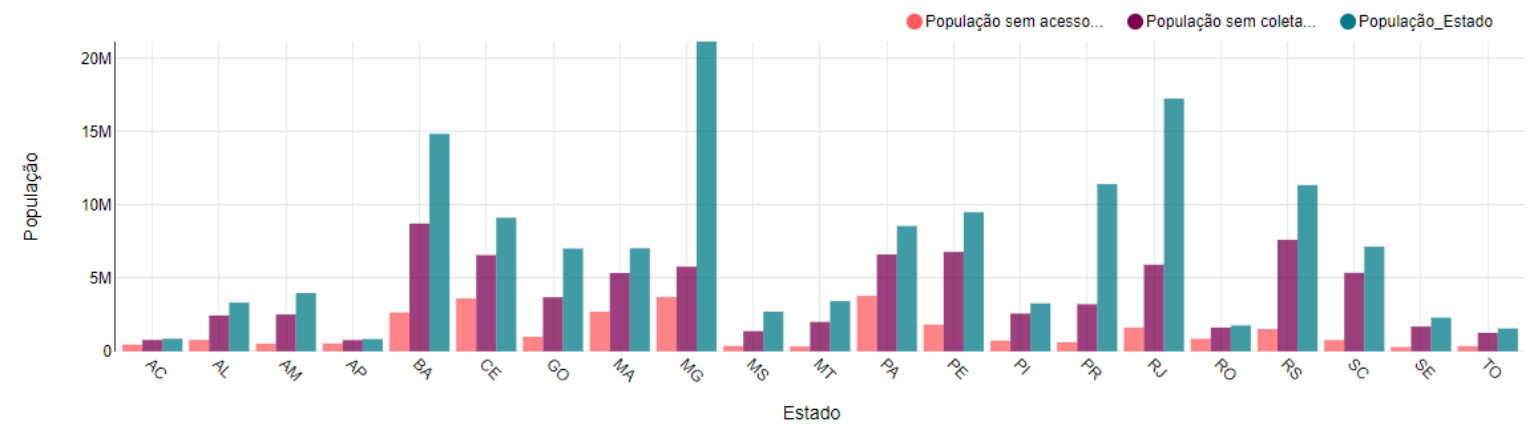

Figura 2. Gráfico em barras com a quantidade de pessoas sem saneamento por estado brasileiro

Aplicando os mesmos dados de pessoas sem acesso à coleta de esgoto e os dados de casos da COVID-19 em gráficos com abordagem espacial, sendo que quanto mais intensa a tonalidade da cor, maior é a quantidade de pessoas sem coleta de esgoto ou maior é a quantidade de casos de COVID-19 (Figura 3), é possível verificar que existe uma forte ligação entre esses fatores a partir da observação do padrão que os dois mapas apresentaram, no qual estados das regiões Sudeste, Nordeste e Norte possuem altos índices de falta de saneamento básico, bem como de casos de COVID-19. 
Segundo estudos por Ahmed et al. (2020), foram encontradas amostras do vírus no esgoto não tratado na Austrália, já outro estudo por Wu et al. (2020) confirmou que o vírus é continuamente eliminado juntamente com as fezes dos pacientes infectados pela doença por um período prolongado, podendo chegar até 27 dias após o primeiro sintoma, sendo detectado até mesmo depois do paciente ter sido curado.
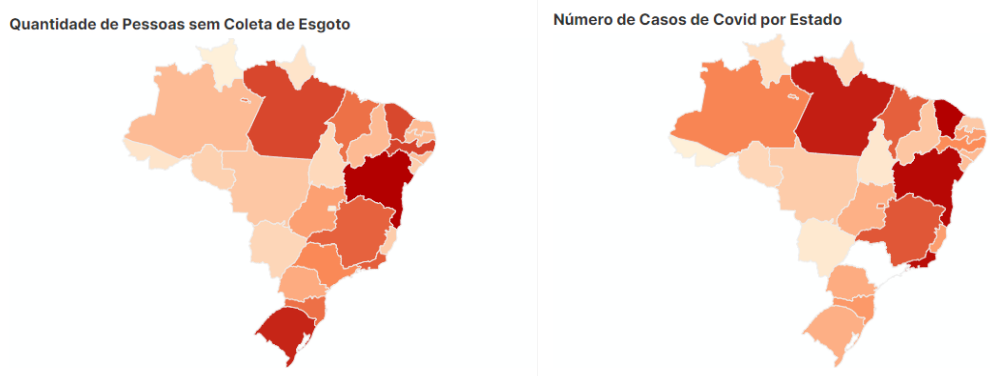

Figura 3. Total de pessoas sem coleta de esgoto por estado e casos acumulados de covid-19 por estado

Foram selecionados os municípios do Brasil com maior índice de idosos, os quais são Santos (SP), Rio de Janeiro (RJ), Niterói (RJ) e Porto Alegre (RS), tal fato pode ser visto na Figura 4, na qual é nota-se que há um deslocamento na faixa etária de 50 anos ou mais. Também foi incluído o município de São Paulo (SP) para comparação.

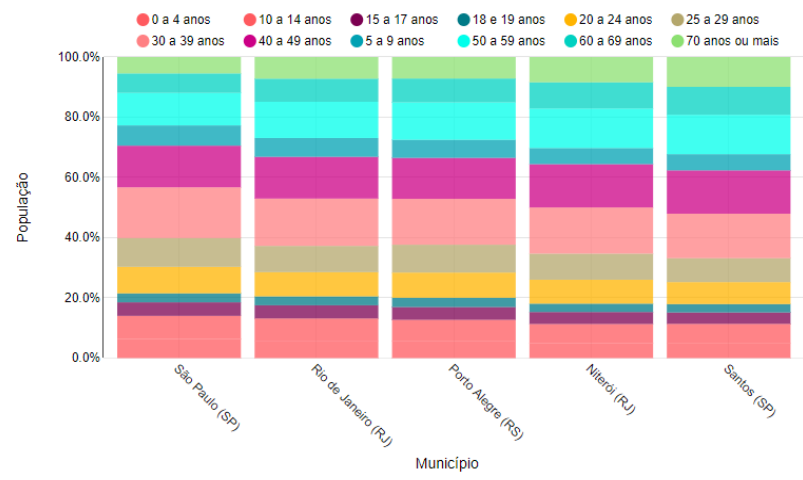

Figura 4. Gráfico em barras mostrando a quantidade de pessoas em cada faixa etária por município

Utilizando as mesmas cidades, criou-se uma visualização com a taxa de mortalidade (mortes / casos confirmados), quantidade total de casos e população estimada para cada uma (Figura 5). Nota-se que municípios com elevado número de pessoas idosas tiverem uma taxa de mortalidade maior mesmo se comparando com municípios que tiveram grande quantidade de casos confirmados da doença como São Paulo.

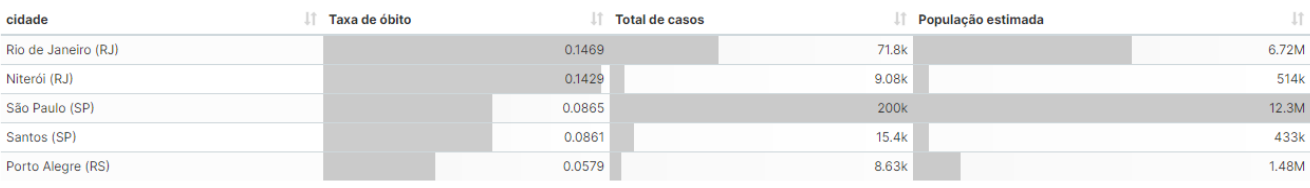

Figura 5. Visualização com taxa de óbito, total de casos e população total estimada por município 


\section{CONCLUSÃO}

Com os dados extraídos de plataformas públicas de saúde foi possível desenvolver conjuntos de dados relacionando os casos da doença COVID-19 com dados demográficos como de população estimada e a quantidade de pessoas por faixa etária, bem como dados de saneamento básico como quantidade de pessoas com acesso à coleta de esgoto e acesso à água. Com os conjuntos de dados criados, foram desenvolvidos as visualizações e gráficos, nos quais foi possível identificar uma forte correlação entre os estados que possuem alto índice de falta de saneamento básico e alto índice de casos confirmados de COVID-19, alinhada às de Mies Bombardi e Luiz Maia Nepomuceno (2020). Além disso, também foi possível observar que municípios com população idosa mais numerosa possuem índices mais elevados de mortalidade pela doença.

No desenvolvimento deste trabalho, também foi observado que o Brasil carece de acessibilidade e qualidade de dados. Apesar disso, foi possível evidenciar informações de qualidade da área da saúde, possibilitando tomadas de decisões mais seguras e abrindo possibilidades para pesquisas futuras. Esse projeto contribui de forma a mostrar que as tecnologias emergentes Dremio e Superset possibilitam a análise de um conjunto de dados por meio da construção de gráficos e dashboards além de oferecer maior acessibilidade por serem gratuitos e de código aberto. Para estudos posteriores, os autores sugerem que outras bases de dados sejam integradas para explorar outros fatores que possam estar relacionados com a disseminação do vírus, tais como as áreas de economia, política e segurança pública.

\section{REFERÊNCIAS}

Ahmed, W. et al, 2020. First confirmed detection of SARS-CoV-2 in untreated wastewater in Australia: A proof of concept for the wastewater surveillance of COVID-19 in the community. Science of The Total Environment, 728, p.138764.

Apache Arrow. 2020. Apache Arrow. [online] Available at: <https://arrow.apache.org/> [Accessed 20 August 2020].

Brasil. Ministério do Desenvolvimento Regional. Secretaria Nacional de Saneamento - SNS. Sistema Nacional de Informações sobre Saneamento, 2018. $24^{\circ}$ Diagnóstico Dos Serviços De Água E Esgotos. [online] Brasília. Available at: 〈http://www.snis.gov.br/downloads/diagnosticos/ae/2018/Diagnostico_AE2018.pdf> [Accessed 19 August 2020].

Dremio. 2020a. The Cloud Data Lake Engine For Big Data Queries. [online] Available at: 〈https://www.dremio.com/> [Accessed 20 August 2020].

Dremio. 2020b. Ensuring an Open Data Lake Future. p.5. Available at: < https://hello.dremio.com/rs/321-ODX117/images/wp_ensuring-an-open-data-lake-future.pdf> [Accessed 25 August 2020].

Freire, S., Souza, R. and Almeida, R., 2015. Integrating Brazilian health information systems in order to support the building of data warehouses. Research on Biomedical Engineering, 31(3), pp.196-207.

EMC. 2020. Executive Summary: Data Growth, Business Opportunities, And The IT Imperatives | The Digital Universe Of Opportunities: Rich Data And The Increasing Value Of The Internet Of Things. [online] Available at: <https://www.emc.com/leadership/digital-universe/2014iview/executive-summary.htm> [Accessed 14 April 2020].

Mies Bombardi, L. and Luiz Maia Nepomuceno, P. (2020). Covid-19, desigualdade social e tragédia no Brasil - Le Monde Diplomatique. [online] diplomatique.org.br. Available at: https://diplomatique.org.br/covid-19-desigualdadesocial-e-tragedia-no-brasil/ [Accessed 28 Aug. 2020].

Ministério da Justiça e Segurança Pública. 2020. Ministério Entrega Aos Estados Primeiras Ferramentas De Big Data E Inteligência Artificial Para Combater A Criminalidade. [online] Available at: $<$ https://www.justica.gov.br/news/collective-nitf-content-1566331890.72> [Accessed 20 August 2020].

Red Hat. 2020. O que é data lake?. [online] Available at: < https://www.redhat.com/pt-br/topics/data-storage/what-is-adata-lake> [Accessed 20 August 2020].

Sankaran, N., 2020. Unlocking Advanced Data Analytics On The Data Lake Using Apache Superset And Dremio. [online] Dremio.com. Available at: 〈https://www.dremio.com/tutorials/dremio-apache-superset/> [Accessed 4 July 2020].

Superset. 2020. Apache Superset (Incubating) - Apache Superset Documentation. [online] Available at: <https://superset.incubator.apache.org/> [Accessed 20 August 2020].

$\mathrm{Wu}$, Y. et al, 2020. Prolonged presence of SARS-CoV-2 viral RNA in faecal samples. The Lancet Gastroenterology \& Hepatology, 5(5), pp.434-435. 